\title{
Urban design, a call for inter-disciplinarity
}

Matthew Carmona

The Bartlett School of Planning, UCL

\section{The models of urban design academe}

Having, over the years, visited many universities across the world in which urban design is taught and researched, it is obvious to me that the positioning of the subject within built environment (and other) faculties often seems compromised. I have observed five models:

- The multiple poles model; where urban design is located separately and independently in the various academic units of a faculty, e.g. architecture, planning, engineering, landscape, or real estate

- The isolated model; where urban design is isolated in one unit or another, with few connections to other academic units that would seem to have an equal claim on the knowledge field

- The fiction model; where on paper a collaborative unit exits that draws expertise from across allied disciplinary units, although on closer inspection is typically either almost entirely dominated by one of these units, or is itself another silo within the range of disciplinary units

- The immersed model; where urban design is not recognised as a separate discipline, but is instead part and parcel of a larger discipline - typically architecture - in which design at the urban scale is sometimes addressed

- The marginal model; the least desirable of the models, where little urban design teaching or research seems to happen at all, and the subject is simply off the radar even of related disciplines.

A sixth, fully integrated model, is of course possible, and there may be shinning examples out their of where urban design sits as an intellectually separate yet also cross-cutting and integrative field within the larger constellation of disciplines. But I have yet to discover such a place. So why is this?

My suspicion is that more often than not urban design is where it is for no good reason at all except administrative convenience. This is because administrative units (departments) within universities are in effect in a competition for resources, both with rival institutions and even with other units within the same university, whilst the currency of that competition is students. Thus with students come resources, and with resources come staff, and academic staff are what makes universities, so if you can attract more students to your unit you have a greater potential to succeed and grow. In such a model, collaboration is not necessarily encouraged (competition is) and because our built environment has traditionally structured itself through its disciplinary professions, these, over time, have become the basis for how we structure our built environment education and compete. 
For urban design, whose scope spans the professions, more often than not the subject develops as an adjunct to one (or more) of these silos, and once created becomes difficult to shift. An interesting side-effect of this is that as urban design develops within the confines of one or other disciplinary home, it also takes on the flavour of that home territory, drawing from the same intellectual traditions, methods and preoccupations that the majority of staff portray. The result is that the nature of urban design, as taught and researched within an architecture school, is likely to be very different to that taught and researched within planning, or landscape, or indeed in any other of its cognate disciplines.

\section{An inter-disciplinary approach}

Take the Bartlett where I work. Because we are lucky enough to be situated in a global university - UCL - in a global city - London - over time the space and demand have existed for four very distinct traditions of urban design to develop in different parts our faculty. First, in the Architecture School where the tradition has been a strongly experimental design one. Second, in the Planning School, where the social sciences, development and governance processes have informed the subject. Third, in the Development Planning Unit, where engagement with the challenges of the Global South bring their own flavour to urban design; and finally, in the Space Syntax Unit where the precepts of space syntax strongly inform a highly analytical approach to teaching and research in urban design.

Having stepped down from being Head of The Bartlett School of Planning in 2011 , I resolved to make it my business to find out more about these very different traditions that had developed quite independently within the same faculty, and to see if we could work more together. In the series of meetings that followed, what became quickly apparent was a similar frustration to that I had felt, but also a profound sense of the richness and legitimacy of each of the traditions that had quite independently taken root in the Bartlett. Also an awareness that, far from being in competition, they were actually quite compatible and complementary in their different perspectives on the city, and on the subject of urban design. Thus whilst we were clearly multiple independent poles (the first of my models above), we were also concerned with many of the same sorts of urban problems and challenges, although tended to draw from different knowledge fields and practices to address them (even, sometimes, seeming to speak different languages to describe them).

The outcome was a series of initiatives that have attempted to find overarching ways to make connections and better reveal both differences and commonalities, whilst maintaining our core identities and the disciplinary traditions that inform them (the legitimacy of which the exercise strongly confirmed). The most significant of these was the instigation of a new cross-cutting masters programme entitled Inter-disciplinary Urban Design. This, for the first time, allows students to cut across the different schools of thought (and administration) 
at the Bartlett (and across UCL) so that students can shape their own unique programmes from the huge diversity of urban design elements on offer, wherever they are locatedi.

As I write this we are now successfully completing the third year of this innovative new programme, and whilst it is small (by comparison to the more disciplinaryfocused programmes on which it feeds), it has attracted consistently high quality students who are not just interested in urban design, but are also interested in its potential as an inter-disciplinary space where cross-cutting ideas can be explored and advanced. This is an approach that the relatively small number of other universities that have nurtured a multiple poles model in urban design might explore. It will also be relevant to the much larger number with isolated or fiction models where the value of a discipline with porous boundaries and where a diversity of contributions, both theoretical and practical, are welcomed and celebrated, needs to be asserted. Immersed and marginal models have other more fundamental problems to address!

\section{Breaching the walls}

I have asserted elsewhere in this journal (Carmona 2014: 2) that urban design is, and is always likely to remain, a mongrel discipline, something to which the sheer range of theories, methodologies, practices and problematics addressed in this journal testifies. Rather than being something that should concern us, this open, accepting, un-blinkered and curious nature of urban design seems to me to be something to celebrate. Sometimes, as we have been doing in the Bartlett, we need to stand back a little in order to see something properly. Education in urban design needs to embrace such an approach, and rather than throwing up new walls around the discipline, wherever it is taught, we should be tearing down those that already surround it care of the allied disciplinary silos within which it so often resides. The model I have described doesn't quite do that, but it certainly breaches them; and perhaps that is good enough.

\section{Reference}

Carmona M (2014) "The Place-shaping Continuum: A Theory of Urban Design Process" Journal of Urban Design, 19(1): 2-36

${ }^{i}$ http://www.bartlett.ucl.ac.uk/planning/programmes/postgraduate/mres/nter-disciplinary-urban-design 